\title{
Influence of consolidation properties on the cyclic re-liquefaction potential of sands
}

\author{
Nurhan Ecemis · Hasan Emre Demirci · Mustafa Karaman
}

Received: 15 April 2014 / Accepted: 4 September 2014 / Published online: 12 September 2014

C Springer Science+Business Media Dordrecht 2014

\begin{abstract}
The relative density can be used as the main indicator to assess the liquefaction resistance of clean sands. As relative density of the sand deposit increases significantly following the initial liquefaction, one should expect that the soil can improve its liquefaction resistance. However, earthquake records indicate that densified sand can be liquefied again (re-liquefied) at smaller cycles by the similar seismic loadings. This work aims to clarify the counterintuitive finding that, after the first liquefaction, the resulting significant increase in relative density (induced by settlements and variation of the water level) do not necessarily imply an increase in the number of loading cycles for re-liquefaction. In this paper, we present a series of experimental results concerning the cyclic liquefaction and the following re-liquefaction of clean sand deposits. The experimental setup is performed by a shaking table, transmitting one-degree of freedom transversal motion to the soil within the $1.5 \mathrm{~m}$ high laminar shear box. At four different seismic demands, the input excitation was imposed three times to examine the influence of the initial distributions of the relative density and the consolidation characteristics on the liquefaction potential of the sand. The re-liquefaction cycles of the sand, which previously experienced liquefaction under the same seismic loadings, show that post-liquefaction reconsolidation of the sand deposits affects the re-liquefaction resistance.
\end{abstract}

Keywords Clean sand - Coefficient of consolidation - Liquefaction resistance . Relative density $\cdot$ Re-liquefaction resistance $\cdot$ Shake table test

\section{Introduction}

Since the earliest studies of sand liquefaction under cyclic loading conditions, it has been well known that the cyclic stresses required to cause initial liquefaction are profoundly prejudiced by the relative density of the soil (Castro and Poulos 1977). As a result of the applied cyclic

N. Ecemis $(\varangle) \cdot$ H. E. Demirci · M. Karaman

Civil Engineering Department, Izmir Institute of Technology, Urla, Izmir 35430, Turkey

e-mail: nurhanecemis@iyte.edu.tr 
shear stresses, the structure of the sand becomes more compact, with a resulting rapid transfer of stress to the pore water and reduction in stress on the sand grains. This causes densification as a result of the shaking-induced settlement and post-liquefaction reconsolidation depending on the intensity of the cyclic loading and consolidation characteristics of the sand deposit after the occurrence of the initial liquefaction. Several case histories indicate that densified sand might not improve its liquefaction resistance and can be liquefied again (re-liquefied) by the subsequent seismic loadings (e.g., Yasuda and Tohno 1988). This phenomenon and the influence of factors on the liquefaction and re-liquefaction resistance of clean sand deposits have been subjected to intensive study by several researchers (e.g., Finn et al. 1970; Ishihara and Okada 1982; Tokimatsu and Hosaka 1986; Suzuki and Suzuki 1988; Mesri et al. 1990; Ohara et al. 1992; Oda et al. 2001; Olson et al. 2005; Ha et al. 2011). There is controversy regarding the reasons for reduction in the re-liquefaction resistance at the smaller or similar seismic loading conditions.

Finn et al. (1970) mentioned that the liquefaction resistance increases when small shear strains are applied on the sand before the cyclic loading test, whereas the sand liquefies easily due to pre-shearing with large shear strains. Based on their studies, the reduction of liquefaction resistance caused by larger shear strains may be due to either the formation of a uniform metastable structure or the development of a non-uniform structure. On the other hand, the increase in liquefaction resistance at small shear strains may be due to the elimination of small local instabilities in the original sand structure. Several other researchers confirmed that the liquefaction resistance significantly increased when small shear strains were applied on the sand, even though there is no significant change in the relative density (Ishihara and Okada 1978; Lee and Albaisa 1974). They discovered that the small preshearing causes a hardening effect in the sample due to plastic yielding. Hence, this plastic yielding signifies a point where the sand deposit becomes less susceptible to liquefaction. Mesri et al. (1990) reported that the increase in the re-liquefaction resistance for loose and medium dense soils may be possible when the relative density increases about 20-30\%. Based on the studies of Oda et al. (2001), the liquefaction resistance of the sand is much more sensitive to its microstructure than its quasi-static strength. According to their work, when the soil is exposed to large shear strain, this large shear strain causes the soil microstructure to change from slightly anisotropic grain into a highly anisotropic structure. This highly anisotropic structure that occurred after the initial liquefaction is instable, and the subsequent shearing process can cause the soil to become deformed easily. Olson et al. (2005) clarified this statement with the aging effect. The destruction of the aged soil structure causes a decrease in the second liquefaction resistance. Furthermore, Olson et al. (2005) showed that low-level shaking (too low to cause significant pore water pressure or liquefaction) increased the liquefaction resistance although the increase in relative density was only $1 \%$. This situation shows that pre-shearing produces better connection among particles and a significant grow in liquefaction resistance. Ha et al. (2011) performed cyclic loading tests to five sands that had differing gradation characteristics. They concluded that liquefaction and re-liquefaction resistances do not correlate well with a single index property such as relative density. Compressibility, as well as the hydraulic conductivity associated with the grain size of the sand, shows a reasonable correlation with re-liquefaction resistance. However, they did not consider the effects of the different cyclic loadings on the liquefaction and re-liquefaction resistance. The related literature points out that there are still uncertainties in the reasons why the re-liquefaction resistance of the sand decreases with an increase in relative density. Hence, there is a need to understand the role of relative density, hydraulic conductivity, compressibility of sands and different cyclic demands on the liquefaction and re-liquefaction resistance. 
In this study, the experimental setup was performed by depositing a total of four loose silica sand with a small effective grain size $\left(D_{10}\right)$ of $0.12 \mathrm{~mm}$ inside the $1.5 \mathrm{~m}$ high flexible aluminum laminar box. The box was composed of 24 rings that could move with low friction against each other and simulate the free-field conditions effectively during different cyclic loadings. The system also involved instrumentation and associated testing hardware to collect detailed data on the progression of liquefaction phenomena during each shaking. A separate paper (Ecemis 2013) presents the quality and reliability of the measured data from the preliminary tests conducted by using the laminar box and shaking table system. A laminar box was placed on the one-degree of freedom shaking table system. A transversal motion was transmitted to the sand within the box under the undrained conditions. At four different seismic demands (CSR), the experiments were performed to detect the existence of liquefaction at various stratum locations. For each CSR, the input excitation was imposed three times to explore the effect of the initial conditions (distribution of the relative density, hydraulic conductivity, compressibility and the coefficient of consolidation) that each shaking test provided to the following one. Before each shaking test, the piezocone penetration tests $(\mathrm{CPTu})$ were performed to evaluate the change in relative density and compressibility of the sand deposits throughout the depth. The measured excess pore water pressure at several locations inside the soil model was used to define the number of sinusoidal cycles required to cause initial liquefaction and re-liquefaction. Minimum $3 \mathrm{~h}$ was introduced between the successive shaking tests in order to fully reconsolidate the sand deposit. At each shaking table test, we explored the role of relative density, post-liquefaction reconsolidation and cyclic loadings on the liquefaction and re-liquefaction resistance of clean sand.

\section{Experimental study}

\subsection{Material}

The fine silica sand was used in the experimental work. Its specific gravity (ASTM D854), minimum (ASTM D4254) and maximum void ratios (ASTM D4253) were found to be 2.61, 0.80 and 0.60 , respectively. From the sieve analysis results (Fig. 1a), it is seen that effective particle size $\left(\mathrm{D}_{10}\right)$ was $0.12 \mathrm{~mm}$ and mean grain size $\left(\mathrm{D}_{50}\right)$ was $0.21 \mathrm{~mm}$. The coefficient of uniformity $\left(C_{u}=D_{60} / D_{10}\right)$ was found as 1.17 . It was defined as poorly graded sand (SP) according to the unified soil classification system. The sand particles used in the experiments were naturally formed sub-angular sand grains which were supplied locally. Figure $1 \mathrm{~b}$ shows the particle shape of the sand grains (SEM picture).

Two consolidated drained triaxial tests were conducted on sand having $30 \%$ relative density. These loose sand samples were prepared by the tamping method under moist conditions to assess the stiffness of the soil. The stress-strain behavior of the soil for initial vertical stress of 100 and $200 \mathrm{kPa}$ is shown in Fig. 2a. The friction angle $(\phi)$ of this sand was determined from the drained triaxial test data as shown in Fig. 2b. It was derived from the Mohr-Coulomb failure criterion and equated to $36^{\circ}$. This friction angle value is consistent with the value measured for similar soils (Koloski et al. 1989).

\subsection{Testing system and model construction}

A total of four loose sand deposits were prepared inside the 1-g laminar box, which had dimensions of $180 \mathrm{~cm} \times 60 \mathrm{~cm}$ in plan and $150 \mathrm{~cm}$ high. The three subsequent shakings were applied to each of these samples by using the one-degree of freedom shake table. The laminar 


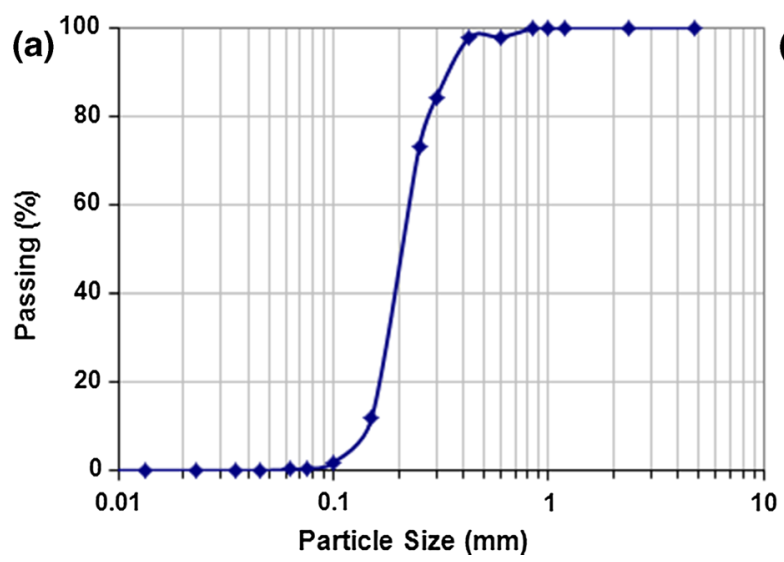

(b)

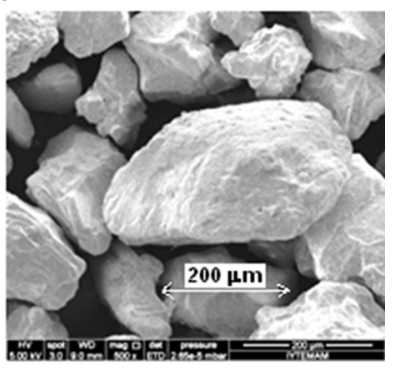

Fig. 1 a The grain size distribution curve and b scanning electron micrograph of the sand used in the shake table tests
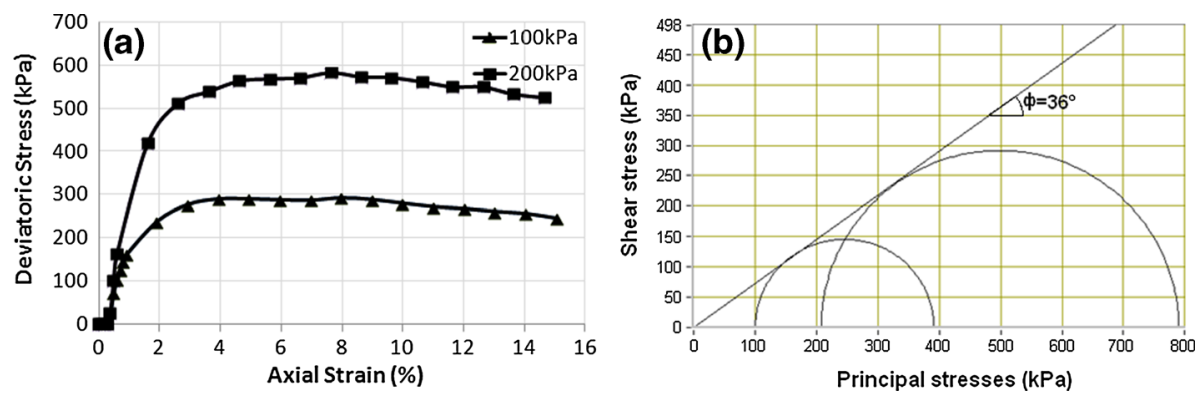

Fig. 2 Results of consolidated drained triaxial test conducted for sand having $30 \%$ relative density

box consisted of 24 identically shaped aluminum rings (referred to as laminates) that moved relative to each other. Aluminum was chosen to reduce the weight of the laminates and their inertial effects on the soil movements. In order to significantly reduce the friction between the layers and to make the distribution of friction uniform, rings were separated and supported by eight rollers ( $47 \mathrm{~mm}$ in diameter) mounted between each laminate.

A $1 \mathrm{~mm}$ thick EPDM rubber membrane was placed inside the box to provide air tightness and to prevent the soil from coming in contact with the laminate walls directly. The stiffness and the thickness of the membrane were chosen in order to not affect the movement of the laminar box. The instrumentation on the laminar box included two potentiometers (X-P1 and X-P2) on the shake table for lateral movement measurements of the shake table. The instrumentation within the soil specimen included five piezometers for measuring the pore water pressure at different depths. In addition, two potentiometers (Z-P1 and Z-P2) were used on the sand surface to measure the surface settlements during and after each shaking table tests. The extension rod end of the potentiometers that recorded the surface settlements were connected to the settlement plate that was laid horizontally on the sand surface. The weight of the plate was chosen as liquefied soil to allow the plate to settle with the soil and prevent it from sinking or floating during testing. The data have been recorded with a common reference time frame and time interval by using the data acquisition system of 47 
(a)

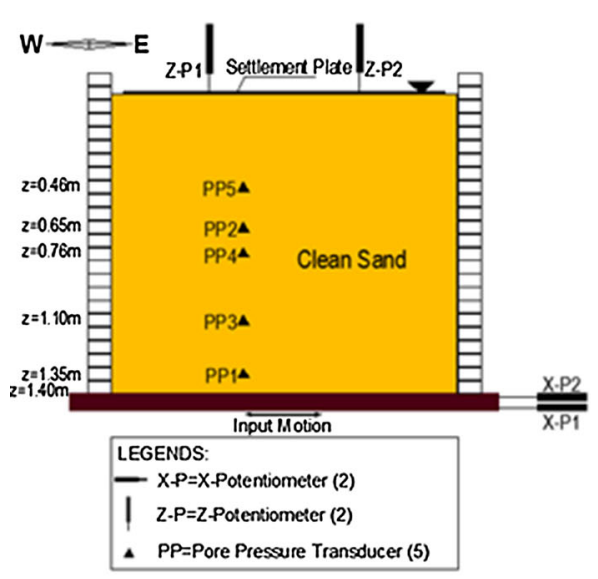

(b)

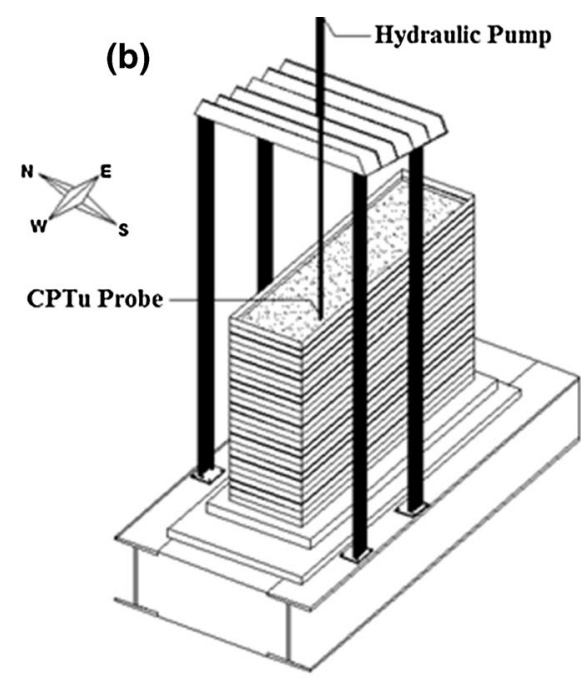

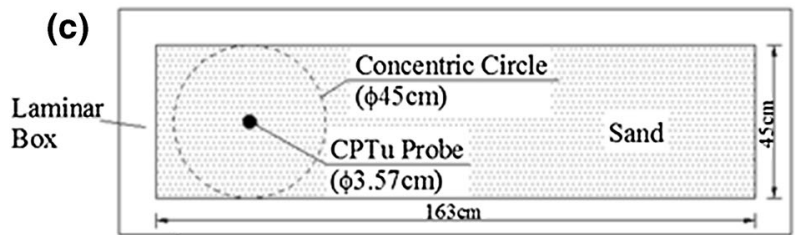

Fig. 3 a The layout plan of the instrumentation, $\mathbf{b}$ cone penetration system and (c) horizontal location of cone penetration in the soil

numbers of channels. Figure 3a shows the layout of the different type of instruments on the shake table and within the soil.

Each of the sand models was prepared in the $0.42 \mathrm{~m}^{3}$ sample preparation basin by mixing the soil samples with water before each test. These samples were then placed in the laminar box by using the hydraulic fill deposition technique (Whitman 1970). This sand placement method allows sand particles to sink slowly through water under the action of gravity. This is like a natural alluvial deposition of sands in rivers or lakes. Following the deposition, aged soil structure was developed from post-depositional mechanical readjustment and weak particle interlocking (Schmertmann 1991). The deposition process involved the following steps:

(1) The membrane was placed inside the box and filled with water to a depth of about $30 \mathrm{~cm}$.

(2) Soil and water mixture from the sample preparation basin was pumped by a slurry pump to place sand uniformly throughout the laminar box.

(3) The soil grains were given time to settle inside the laminar box.

(4) After some time, water pump was used to deliver the excess water from the laminar box back to the sample preparation basin.

This closed-loop pumping system was adjusted to maintain average $30 \mathrm{~cm}$ height of water above the sand surface inside the laminar box to achieve the loose deposition. Almost the top $30 \mathrm{~cm}$ of the soil inside the box was found to be slightly denser than the soil at the bottom, due to the limitation of maintaining the $30 \mathrm{~cm}$ water near the top of the box. This reduction in the water height on the soil surface increased the relative density of the soils due to change 
in the settling heights of the sand particles. This cycle was maintained until the height of the saturated loose clean sand sample in the laminar box reached $1.4 \mathrm{~m}$. More details about the physical modeling (laminar box) and shaking table system can be found at Ecemis (2013).

\section{Shake table and piezocone penetration test results}

As summarized in Table 1, a total of four sand deposits were prepared and tested inside the laminar box. These soils were subjected to individual sinusoidal motions for $12 \mathrm{~s}$ with different peak ground accelerations (PGA) of $0.05,0.10,0.16$ and $0.21 \mathrm{~g}$. For each cyclic loading, the input excitation was imposed three times under the undrained conditions. The applied frequency for each shake was $2 \mathrm{~Hz}$. This frequency was selected to ensure a better control of the large scale laminar box and shaking table system (Ecemis 2013). It is also recognized that frequency employs negligible effect on the cyclic liquefaction resistance of sand deposits (Lee and Fitton 1969; Wong et al. 1975). The multi-directional shaking and modes of shear of the strong shaking in the field were different from those in the laboratory. Therefore, the peak ground accelerations used for the sine-wave based laboratory experiments should be scaled up by a factor of $1 / 0.65$ in order to achieve real behavior of soil during the earthquake (Seed and Idriss 1971). The levels of base shaking used for this study are summarized in Table 1 with the equivalent PGA values as recommended by Seed and Idriss (1971).

The cyclic stress ratio (CSR) was determined from the equation proposed by Seed and Idriss (1971).

$$
\operatorname{CSR}=0.65\left(\frac{\mathrm{a}_{\mathrm{max}}}{\mathrm{g}}\right)\left(\frac{\sigma_{\mathrm{vo}}}{\sigma_{\mathrm{vo}^{\prime}}}\right) \mathrm{r}_{\mathrm{d}}
$$

where $\sigma_{\mathrm{vo}}=$ total initial vertical stress, $\mathrm{g}=$ acceleration of gravity, $\mathrm{r}_{\mathrm{d}}=$ stress reduction factor varying linearly from a value of 1.0 at the soil surface to a value of 0.9 at a depth of about $9 \mathrm{~m}$ (Seed and Idriss 1971) and $\mathrm{a}_{\max }=$ maximum acceleration that was taken account as equivalent PGA. Since there is only one soil strata inside the laminar box, $\left(\sigma_{\mathrm{vo}} / \sigma_{\mathrm{vo}^{\prime}}\right)$ was equal to $\gamma /\left(\gamma-\gamma_{\mathrm{w}}\right)$. Where $\gamma=$ saturated unit weight of sand and $\gamma_{\mathrm{w}}=$ unit weight of

Table 1 Levels of shaking and cyclic stress ratio
CSR Cyclic siress ratio, $P G A$ peak ground acceleration, $(P G A)_{\text {eq }}$ equivalent peak ground

\begin{tabular}{|c|c|c|c|c|}
\hline Shake table test no. & Shake number & $\begin{array}{l}\text { PGA } \\
\mathrm{g}\end{array}$ & $\begin{array}{l}(\mathrm{PGA})_{\mathrm{eq}} \\
\mathrm{g}\end{array}$ & $\overline{C S R}$ \\
\hline Test 1 & $\begin{array}{l}\text { 1st Shake } \\
\text { 2nd Shake } \\
\text { 3rd Shake }\end{array}$ & 0.05 & 0.08 & 0.11 \\
\hline Test 2 & $\begin{array}{l}\text { 1st Shake } \\
\text { 2nd Shake } \\
\text { 3rd Shake }\end{array}$ & 0.10 & 0.15 & 0.21 \\
\hline Test 3 & $\begin{array}{l}\text { 1st Shake } \\
\text { 2nd Shake } \\
\text { 3rd Shake }\end{array}$ & 0.16 & 0.25 & 0.35 \\
\hline Test 4 & $\begin{array}{l}\text { 1st Shake } \\
\text { 2nd Shake } \\
\text { 3rd Shake }\end{array}$ & 0.21 & 0.32 & 0.46 \\
\hline
\end{tabular}
accelerations 


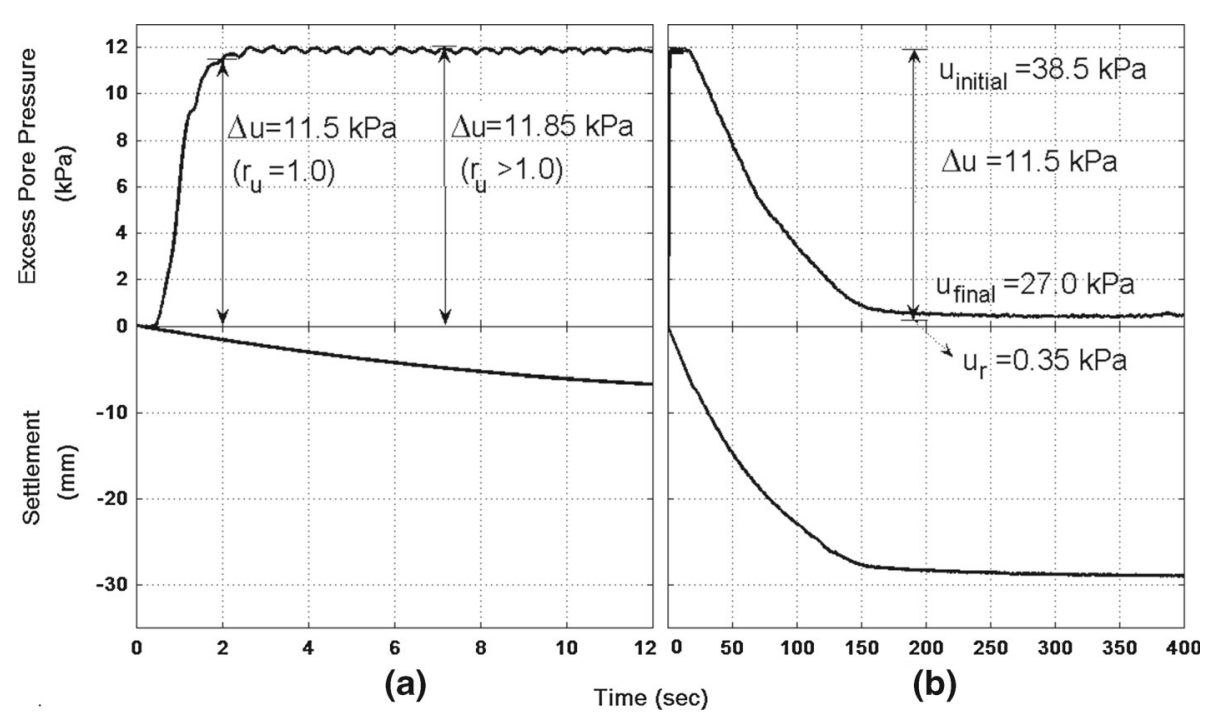

Fig. 4 The change of excess pore pressure and surface settlement with time (a) during and (b) following Test 3 , initial shake at a depth of $1.35 \mathrm{~m}$

water. The saturated unit weight of the soil was measured by $10 \mathrm{~cm}$ diameter and $7 \mathrm{~cm}$ high cylindrical steel buckets. They were placed inside the laminar box at four different depths during the hydraulic filling process, and then removed when the buckets were filled with the sample. The average saturated unit weight of the prepared samples ranged from 17 to $19 \mathrm{kN} / \mathrm{m}^{3}$ throughout the depth, with an average for the entire deposit close to $18 \mathrm{kN} / \mathrm{m}^{3}$. To exemplify, for Test $1, \gamma /\left(\gamma-\gamma_{\mathrm{w}}\right)$ was found about 2.2. At a depth of $1.4 \mathrm{~m}$, the stress reduction factor was determined 0.99. For equivalent PGA of $0.08 \mathrm{~g}$, CSR value was 0.11 . The CSR values at each shaking test are also listed in Table 1.

\subsection{Excess pore water pressure time histories}

The number of sinusoidal cycles required to cause liquefaction and re-liquefaction was determined by multiplying the time when the liquefaction started to occur with $2 \mathrm{~Hz}$ frequency of the seismic motion. The time when the liquefaction triggered for each test was determined based on the excess pore water pressure $(\Delta u)$ time history records which were specified with the aid of piezometers placed at five different depths.

As the liquefaction time is the most-important factor in this paper, it is essential to illustrate the determination of the liquefaction time in detail by using one of the test results. Figure $4 \mathrm{a}$, b show the alteration of excess pore water pressure and settlement at Test 3 (initial shake at a depth of $1.32 \mathrm{~m}$ ). In general, liquefaction often occurs when the ratio of excess pore water pressure to effective vertical stress $\left(r_{u}=\Delta u / \sigma_{v o}^{\prime}\right)$ reaches a value of 1.0. However, in most cases due to the permanent changes in total stress, the peak value of $r_{u}$ corresponding to a liquefied height found remarkably bigger than 1.0. Several researchers also recorded the pore pressure ratio more than 1.0 (e.g. Fiegel and Kutter 1994). This difference may arise due to settlement of the piezometers and/or a rise in the water table elevation. As shown in Fig. 4a, the excess pore pressure generated during the shaking was determined as $11.85 \mathrm{kPa}$. This figure also shows settlement time history recorded by the potentiometers placed on the sand surface during the same test. The recorded settlement at the end of the shaking (at $12 \mathrm{~s}$ ) was around 


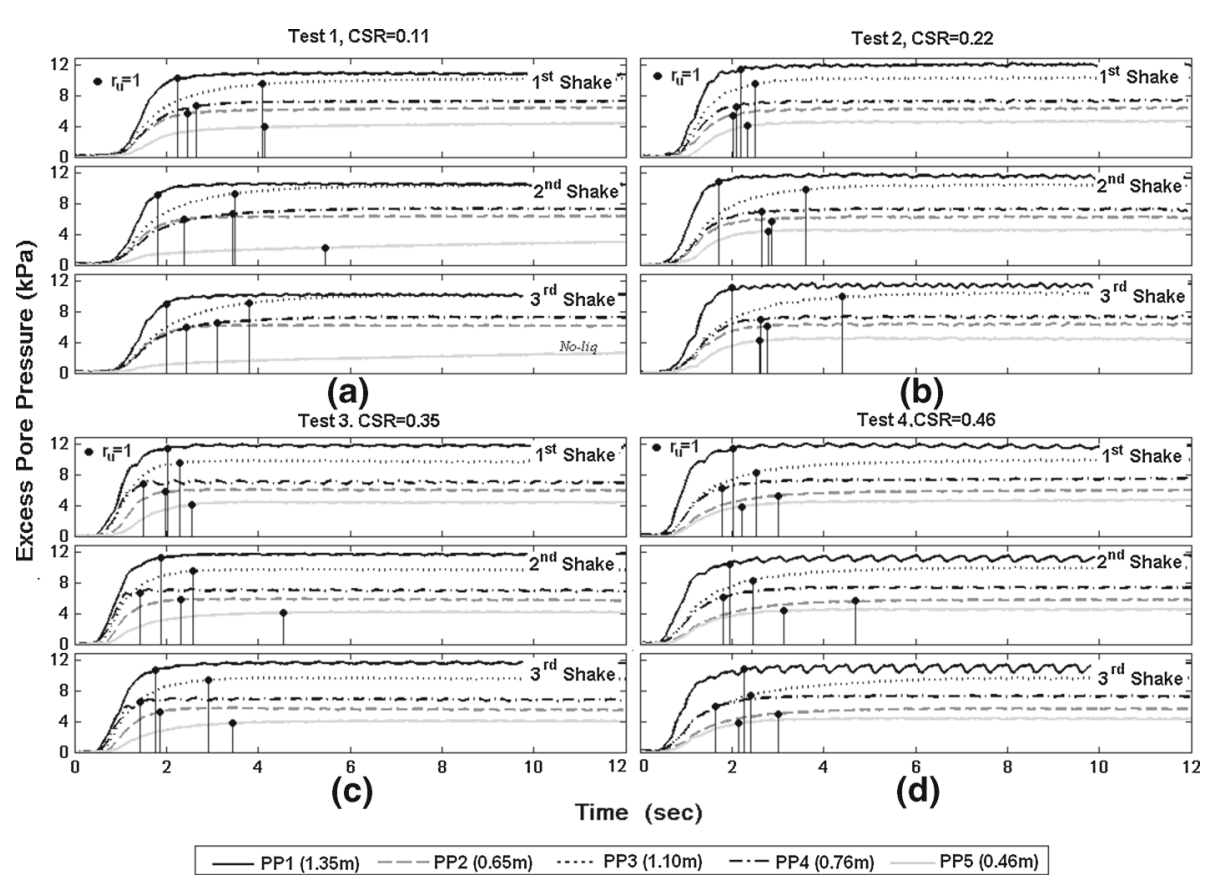

Fig. 5 The change of excess pore pressure with time recorded at (a) Test 1, (b) Test 2, (c) Test 3 and (d) Test 4

$0.76 \mathrm{~cm}$. As illustrated in Fig. 4b, the excess pore pressure generated during the shaking has essentially dissipated; however, the pore pressure has not returned to its initial value. The dissipated excess pore water pressure was determined as $11.5 \mathrm{kPa}$. The residual pore pressure $\left(\mathrm{u}_{\mathrm{r}}\right)$ was obtained as $0.35 \mathrm{kPa}$. The settlement of the piezometer was calculated to be around $3.56 \mathrm{~cm}$ by dividing the residual pore water pressure after dissipation by the unit weight of water. Figure $4 \mathrm{~b}$ also shows settlement time history recorded during and after the shaking. At $400 \mathrm{~s}$, the potentiometers recorded the total settlement around $3.0 \mathrm{~cm}$. The settlement calculated from the residual pore water pressure correlates well with the surface settlement which supports the idea that the residual pore pressure is a result of piezometer settlement. Therefore, in this study, the liquefaction triggering times were evaluated by considering the settlement of the piezometers.

Figure $5 \mathrm{a}-\mathrm{d}$ show the time when the liquefaction triggered for each shaking test. The initial depth of the piezometers inside the sand model is illustrated at the bottom of the figure. The dots on the $\Delta \mathrm{u}$-time history plots indicate the liquefaction triggering times. The excess pore water pressure time histories display that the excess pore pressure increased with an increase in the cycles of shaking at a linear rate throughout the entire sand deposit until the liquefaction was triggered. The initiation of liquefaction was random and non-sequential throughout the depth of the sand deposits. It is recognized that the saturated sand can have significantly different liquefaction resistance depending on how it is prepared to any density (Mulilis et al. 1977; Tatsuoka et al. 1986). The hydraulic fill deposition technique used in this study allowed sand particles to sink slowly through water under the action of gravity. However, it was not possible to maintain the same level of water above the sand surface during the deposition of the sand. This significant alteration in the settling heights of the 
sand particles caused different relative density and particle interlocking which affected the liquefaction resistance throughout the depth.

\subsection{Cone penetration resistance and relative density}

The piezocone penetration tests $(\mathrm{CPTu})$ were performed to evaluate the relative density of the sand prior to each shaking test. As displayed in Fig. $3 \mathrm{~b}$, the $60^{\circ}$ tapered, $10 \mathrm{~cm}^{2}$ tip area cone (diameter of $3.57 \mathrm{~cm}$ ) penetrated into the soil at a constant penetration rate of $2 \mathrm{~cm} / \mathrm{s}$ (ASTM D3441) by using a hydraulic pump. The horizontal location of the cone penetration in the soil is shown in Fig. 3c. The CPTu tests provided measurements of cone penetration resistance $\left(\mathrm{q}_{\mathrm{c}}\right)$, friction resistance $\left(\mathrm{f}_{\mathrm{s}}\right)$ and pore water pressure $\left(\mathrm{u}_{2}\right)$ values along the depth. Before each shaking the $\mathrm{q}_{\mathrm{c}}$ values that were measured throughout the depth by CPTu tests are shown in Fig. 6a-d. The cone penetration resistance was also estimated from the friction angle that was obtained from the triaxial tests. By using the relationship given by Robertson and Campanella (1983), for $36 \%$ friction angle, cone penetration resistance was determined less than $1,000 \mathrm{kPa}$ which is consistent with the recorded values from the CPTu tests.

At all CPTu tests, we observed a reduction at $\mathrm{q}_{\mathrm{c}}$ values between 0.6 and $0.8 \mathrm{~m}$ depths. At any depth between 0.6 and $0.8 \mathrm{~m}$, the CPTu recording was paused, and additional rod was manually attached to the penetration system. When penetration was started again, at $2-4 \mathrm{~cm}$ depth range, $\mathrm{q}_{\mathrm{c}}$ data detected less than the actual values. Besides, at Test 1 (Fig. 6a), during the last two CPTu tests, a sudden increase at $\mathrm{q}_{\mathrm{c}}$ values was observed after $1.1 \mathrm{~m}$ depth. Before filling the box with sand, we mounted the piezometers vertically on a plastic net and placed it inside the laminar box. During the penetration of the cone inside the soil, the probe pulled the instrumentation net between 1.1 and $1.3 \mathrm{~m}$ depths. Hence, this tension force caused a sudden increase at $\mathrm{q}_{\mathrm{c}}$ values. Also, at Test 2 (Fig. $6 \mathrm{~b}$ ), $\mathrm{q}_{\mathrm{c}}$ data from 0.7 to $1.3 \mathrm{~m}$ are not shown in the figure due to a recording error during the CPTu test conducted before the second shake. These measurement inaccuracies at certain depths were evaluated with caution when evaluating the data.

The CPTu measurements can be affected by the box size and boundary conditions. Several researchers (Parkin and Lunne 1982; Phillips and Valsangkar 1987; Renzi et al. 1994) have observed the effects of boundary conditions on CPTu data and have proposed a diameter ratio, defined as $R_{d}$, to decide whether boundary effects on the CPTu measurements are significant. $R_{d}$ is identified as the ratio of box diameter to cone diameter. Parkin and Lunne (1982) stated that the side boundary effects depend on the relative density of the sand. For loose sand with a relative density on the order of $30 \%$, the side boundary effects are negligible (Parkin and Lunne 1982). Phillips and Valsangkar (1987) reported that for dense sands with a relative density on the order of $85 \%$, the side boundary effects are not significant even when the probe is located at a distance from the wall corresponding to $R_{d}=5$. Renzi et al. (1994) prepared specimens at high densities in a cylindrical container and showed no apparent increase in cone penetration resistance for tests conducted at $R_{d}=11$ as compared to $R_{d}=22$. In this study, cone penetrations were performed along one concentric circle, with the outer circle being $45 \mathrm{~cm}$ from the laminar box edge. Using $45 \mathrm{~cm}$ as the distance to the wall gives $R_{d}$ value 13 for the cone that has a diameter of $3.57 \mathrm{~cm}$. The effects of the boundary conditions on the recorded CPTu data are satisfactory in the scope of the liquefaction tests when $\mathrm{R}_{\mathrm{d}}$ values reported in the literature are considered.

The relative density along the soil depth was indirectly determined from the measured cone penetration resistance by using the empirical relationship given by Jamiolkowski et al. (1985). 


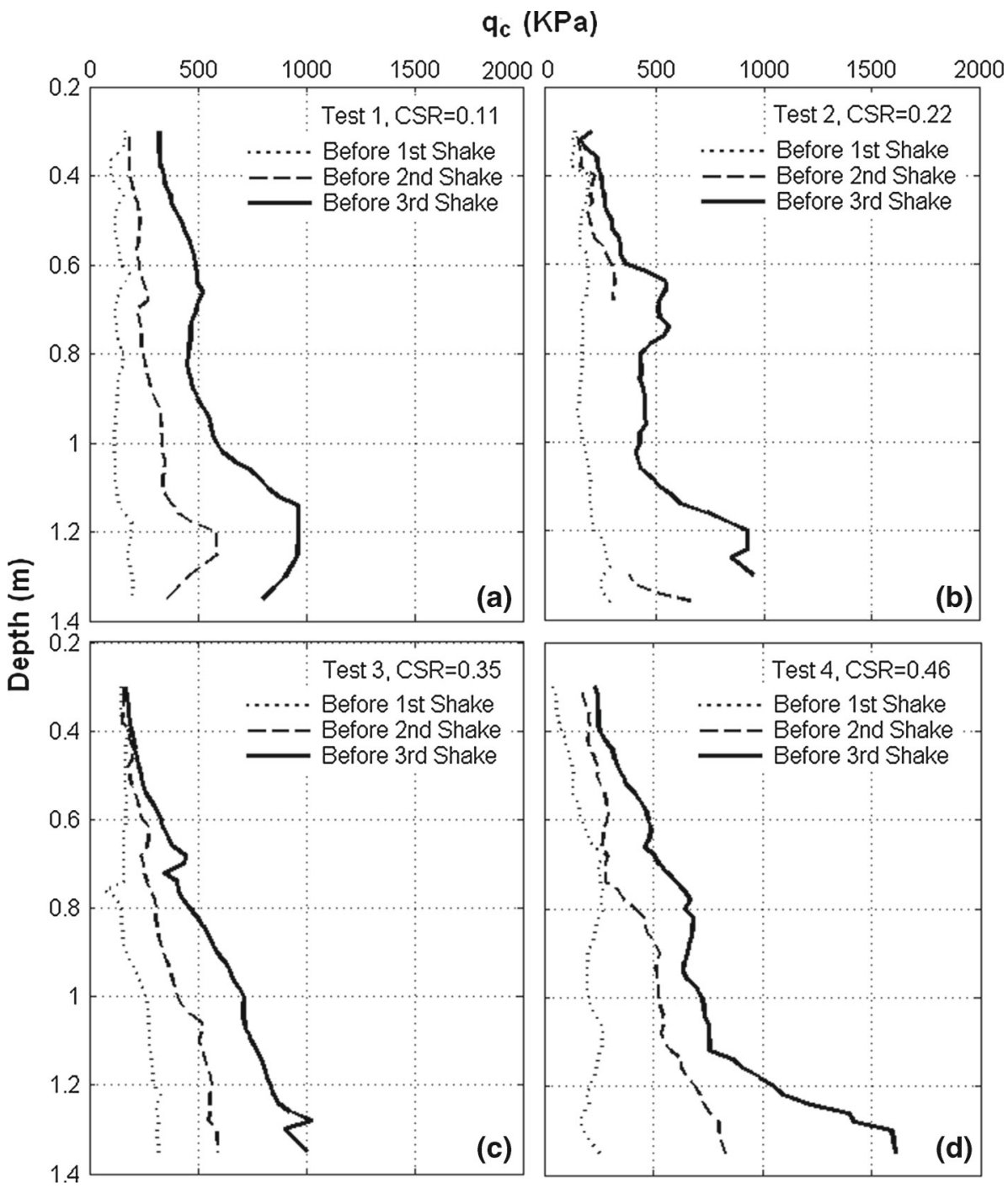

Fig. 6 Measured cone penetration resistance along the depth from CPTu at (a) Test 1, (b) Test 2, (c) Test 3 and (d) Test 4

$$
\mathrm{D}_{\mathrm{r}}=-98+66 \times \log _{10}\left(\frac{\mathrm{q}_{\mathrm{c}}}{\sqrt{\sigma_{\mathrm{vo}}^{\prime}}}\right)
$$

where $D_{r}=$ relative density in percentage; $\sigma_{v o}^{\prime}=$ effective initial vertical stress in $\mathrm{kPa}$, and $\mathrm{q}_{\mathrm{c}}=$ measured cone penetration resistance in $\mathrm{kPa}$. In order to verify empirical relation given in Eq. (2), the initial relative density of the soil along the depth was directly measured by cylindrical steel buckets. They were placed inside the laminar box at four different depths during the hydraulic filling, and then removed when the buckets were filled with the sample. To exemplify, Fig. 7 shows the initial relative density throughout the depth at Test 3 . The relative density profiles were obtained from the bucket density tests and relative density 
Fig. 7 Initial relative density from the bucket density and CPTu tests along the depth at Test 3 , before the first shake
Relative density, $\mathrm{D}_{\mathrm{r}}(\%)$

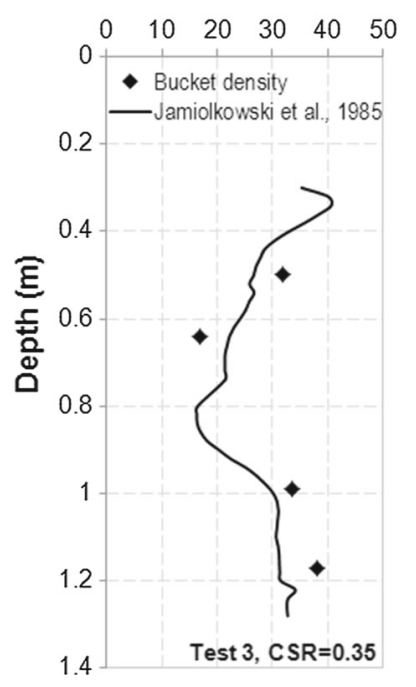

correlation given by Jamiolkowski et al. (1985). The relative density of the prepared sample was determined 15-40\% throughout the depth, with an average for the whole deposit close to $25 \%$. The relative density measurements obtained using the steel buckets ranged from 18 to $38 \%$ throughout the depth. This range obtained from the cylindrical steel buckets was reasonably good with the relative density range estimated from Eq. (2). These values are also consistent with the relative density intervals measured immediately after deposition in clean sand hydraulic fills (Whitman 1970; Poulos and Hed 1973; Mitchell et al. 1999; Thevanayagam et al. 2009).

\subsection{Settlement time histories}

Surface settlement time histories during the shakings and during reconsolidation, measured by the potentiometers placed on the sand surface for each test. In order to understand the post-liquefaction consolidation process, the surface settlements are plotted in Fig. 8a-d with the pore water pressure dissipations $(\Delta \mathrm{u})$ along the same time axis. The results show that the sand deposits fully reconsolidated as sufficient time (at least $3 \mathrm{~h}$ ) was introduced between the successive shakings. The significant settlements and void redistributions occurred at the sand surface during the initial shaking and during the reconsolidation following the shaking. The figures illustrate that at each test, the majority of the settlement occurred following the first shaking as the initially loose sand densified. Moreover, the amount of settlement reduced during the second and third shakings.

Based on the settlement time histories of Test 1 (Fig. 8a), the magnitudes of total vertical strains $\left(\varepsilon_{\mathrm{v}}\right)$ for the first, second and third shakings were almost 2.3, 1.2 and $0.8 \%$, respectively. At Test 2 (Fig. 8b), the magnitudes of $\varepsilon_{\mathrm{v}}$ for the first, second and third shakings were around 1.9, 1.6 and $1.2 \%$, respectively. At Test 3 (Fig. 8c), the magnitudes of $\varepsilon_{\mathrm{v}}$ for the first, second and third shakings were approximately 2.0, 1.6 and $0.9 \%$, respectively. At Test 4 (Fig. 8d), the magnitudes of $\varepsilon_{\mathrm{v}}$ for the first, second and third shakings were about 2.6, 1.6 and $0.8 \%$, respectively. Apparently, the amplitudes of net vertical strains do not increase monotonically with the shaking intensity. We attribute this observation to the alteration of the 


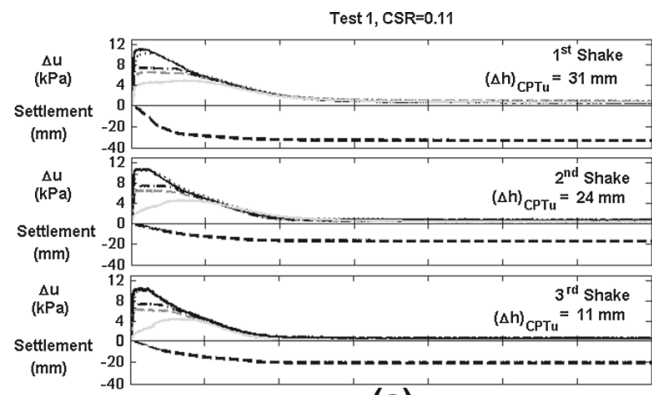

(a)

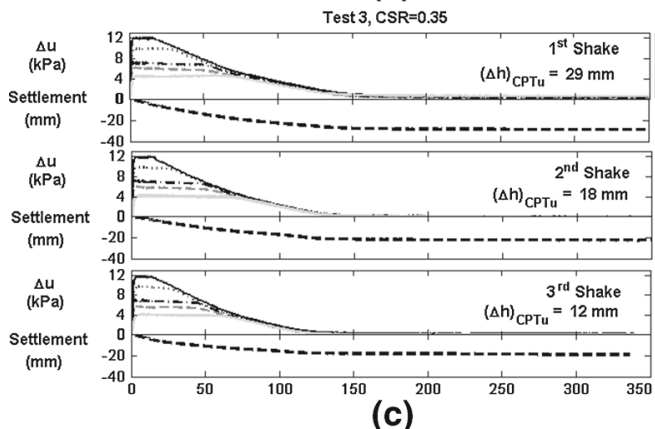

(c)

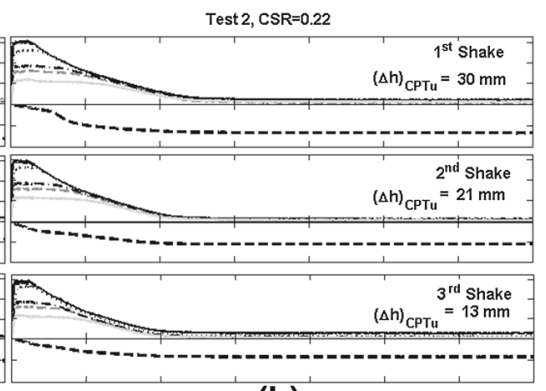

(b)

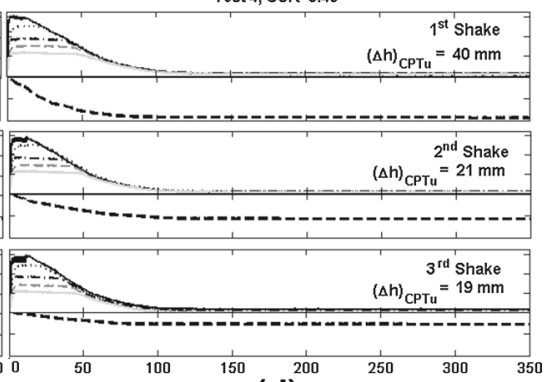

(d)

— PP1 $(1.35 \mathrm{~m})---\mathrm{PP} 2(0.65 \mathrm{~m}) \quad \cdots \cdot \mathrm{PP} 3(1.10 \mathrm{~m}) \quad-\cdot-\mathrm{PP} 4(0.76 \mathrm{~m}) \_$PP5 $(0.46 \mathrm{~m}) \quad---$ Potentiometer

Fig. 8 Surface settlement time history and pore pressure dissipation results for (a) Test 1, (b) Test 2, (c) Test 3 and (d) Test 4

relative density throughout the depth. In order to verify the above given settlement results, the direct measurements of settlements from potentiometers were compared with the estimated settlements $(\Delta \mathrm{h})$ from the CPTu data:

$$
(\Delta \mathrm{h})_{\text {CPTu }}=\frac{\mathrm{h} \Delta \mathrm{e}}{1+\left[\mathrm{e}_{\max }-\mathrm{D}_{\mathrm{r}, \text { ave }}\left(\mathrm{e}_{\max }-\mathrm{e}_{\min }\right)\right]}
$$

where $D_{r, \text { ave }}=$ average relative density throughout the depth that was calculated by means of CPTu data recorded before each shake test, $\mathrm{e}_{\max }=$ maximum void ratio found to be 0.8 , $\mathrm{e}_{\min }=$ minimum void ratio found to be $0.6, \Delta \mathrm{e}=$ change of void ratios at each shaking test, $\mathrm{h}=$ height of the soil deposit. For each shake, the calculated $(\Delta \mathrm{h})_{\mathrm{CPTu}}$ values are given in Fig. $8 \mathrm{a}-\mathrm{d}$ with the surface settlement and excess pore pressure time histories. These results show that the calculated total settlements from CPTu reasonably accord with the measured settlements. The magnitudes of net vertical strain observed in this study are also compatible with strains measured in the field and laboratory liquefaction tests at level grounds (Tokimatsu and Seed 1987; Ishihara and Yoshimine 1996).

\section{Effect of relative density on liquefaction and re-liquefaction resistance}

The above mentioned shaking table test results enable us to find the influence of relative density on the liquefaction and re-liquefaction potential of the sand. Figure 9a shows the initial relative densities $\left(\mathrm{D}_{\mathrm{r} \text {,initial }}\right)$ prior to each shaking test at five different locations of 


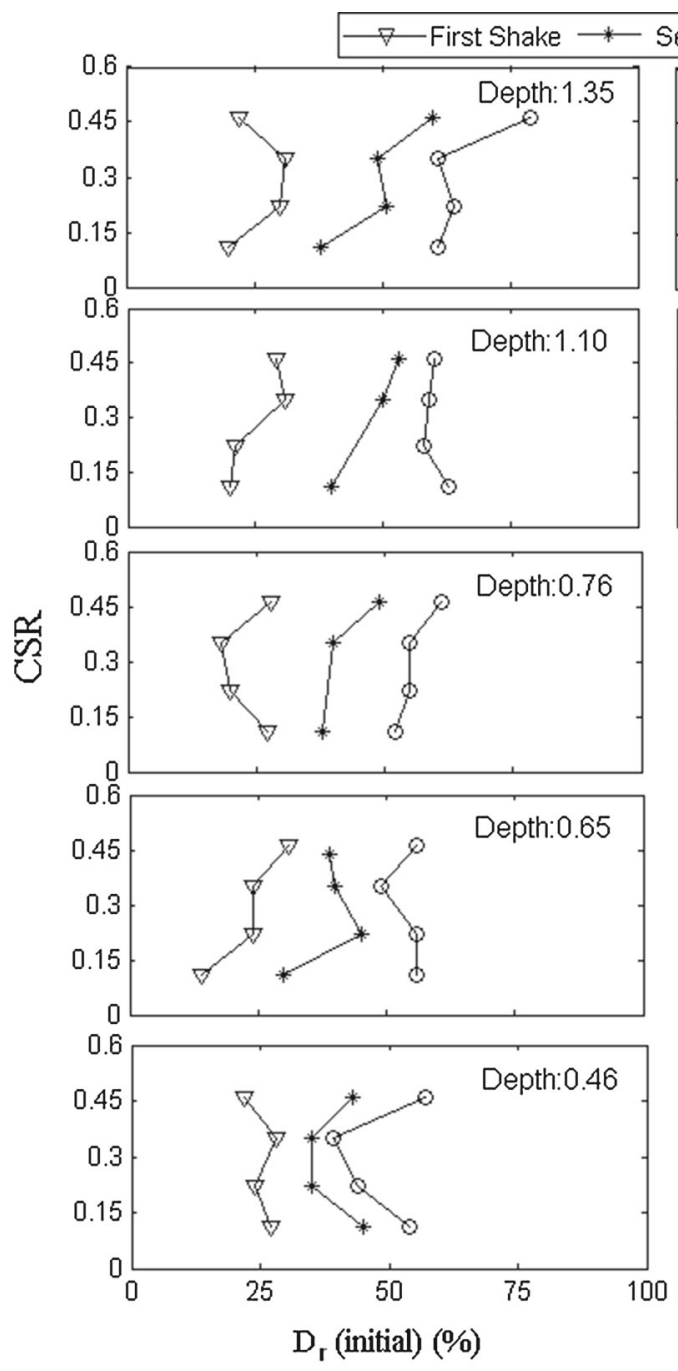

(a)
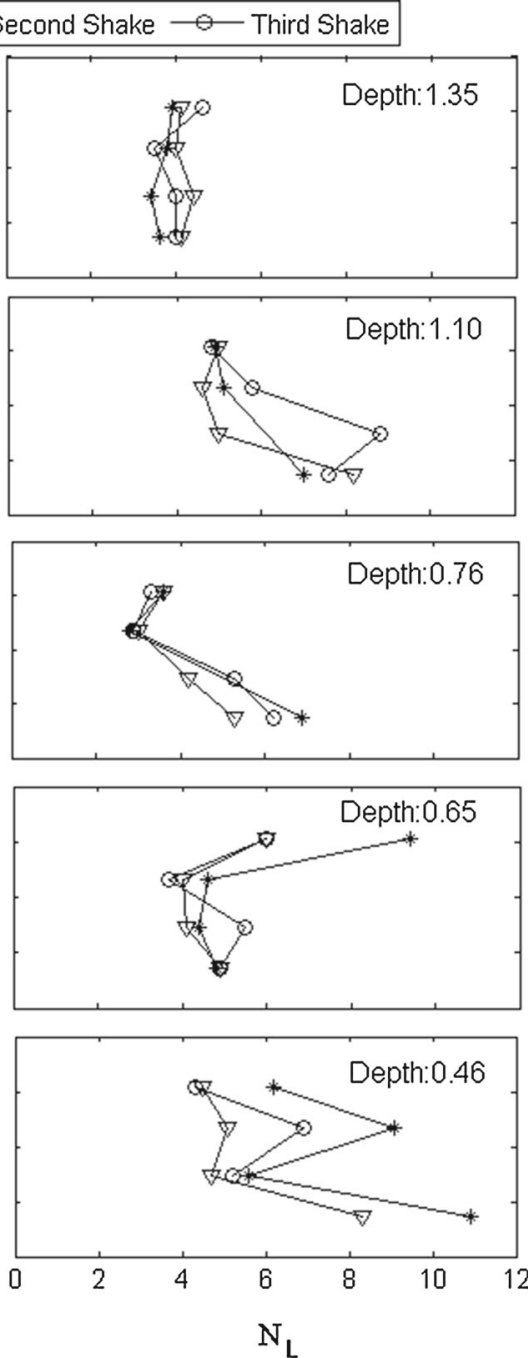

(b)

Fig. 9 Variation of cyclic stress ratio with (a) initial relative density and (b) number of cycles required to cause liquefaction and re-liquefaction at five different depths

$1.35,1.10,0.76,0.65$ and $0.46 \mathrm{~m}$ in the sand profile. Initial relative densities for the tested sands prior to the first shaking test ranged from about 15 to $40 \%$. At each cyclic loading, we observed a pronounced increase in relative density from initial liquefaction to second liquefaction. After the first shaking, relative densities increased to values of about $35-60 \%$. During the second shaking test, sand deposit also experienced an increase in relative density. This significant increase in relative densities was due to the dissipation of excess pore water pressure and the consolidation settlement after and during liquefaction.

Figure $9 \mathrm{~b}$ illustrates the number of cycles required to cause initial, second and third liquefaction $\left(\mathrm{N}_{\mathrm{L}}\right)$ at several stratum locations in the sand profile. In this paper, the resistance to 
liquefaction was represented by the number of sinusoidal cycles that are required to cause liquefaction and re-liquefaction. As shown in the figures, large enough excess pore pressure was not developed to liquefy the sand at CSR of 0.11 and depth of $0.46 \mathrm{~m}$ during the third shaking. For four different cyclic/seismic intensities, the sand re-liquefied throughout its almost entire profile during all subsequent shakings, despite an increase in relative density resulting from shaking and reconsolidation. Also, both increases and decreases in the re-liquefaction resistance of the sand deposits were recorded at each CSR. These trends demonstrate that the amount of increase in relative density cannot possibly be the main reason for the liquefaction resistance and re-liquefaction resistance of sand deposits. There should be other factors, which may play a crucial role in the change to the re-liquefaction resistance of the sand deposits, rather than the sole relative density.

\section{Consolidation characteristics of sand}

Several constant head permeability tests (ASTM E2396) were performed in the laboratory in order to measure the hydraulic conductivity $(\mathrm{k})$ of the sand at different relative densities. Figure 10 shows the variation of hydraulic conductivity against relative density of the fine silica sand that had effective grain size of $0.12 \mathrm{~mm}$. For the sand sample used in this study, the following relationship was determined between the hydraulic conductivity and relative density:

$$
\mathrm{k}=0.029 \mathrm{e}^{-0.03 \mathrm{D}_{\mathrm{r}}}
$$

In the literature, many correlations are available in order to estimate the compressibility of the soils from the measured cone penetration resistance (Sanglerat 1972; Kulhawy and Mayne 1990; Robertson 2009). In this study, the compressibility of the clean sand was estimated from the CPTu tests based on the correlation proposed by Robertson (2009):

$$
\mathrm{m}_{\mathrm{v}}=\frac{1}{\alpha_{\mathrm{M}}\left(\mathrm{q}_{\mathrm{t}}-\sigma_{\mathrm{vo}}\right)}
$$

if $\mathrm{I}_{\mathrm{c}}>2.2$ and $\mathrm{q}_{\mathrm{c} 1 \mathrm{~N}}<14$ then $\alpha_{\mathrm{M}}=\mathrm{q}_{\mathrm{c} 1 \mathrm{~N}}$,

if $\mathrm{I}_{\mathrm{c}}>2.2$ and $\mathrm{q}_{\mathrm{c} 1 \mathrm{~N}}>14$ then $\alpha_{\mathrm{M}}=14$,

if $\mathrm{I}_{\mathrm{c}}<2.2$ then $\alpha_{\mathrm{M}}=0.03\left[10^{\left(0.55 \mathrm{I}_{\mathrm{c}}+1.68\right)}\right]$

where $\mathrm{q}_{\mathrm{t}}=$ corrected total cone resistance, and $\mathrm{I}_{\mathrm{c}}=\left[\left(3.47-\log _{10} \mathrm{q}_{\mathrm{c} 1 \mathrm{~N}}\right)^{2}+\left(\log _{10} \mathrm{~F}+\right.\right.$ $\left.1.22)^{2}\right]^{0.5}$ is the soil behavior type index which is modified by Robertson and Wride (1998).

Fig. 10 The relationship

between the hydraulic conductivity and relative density for the fine silica sand that has effective grain size of $0.12 \mathrm{~mm}$

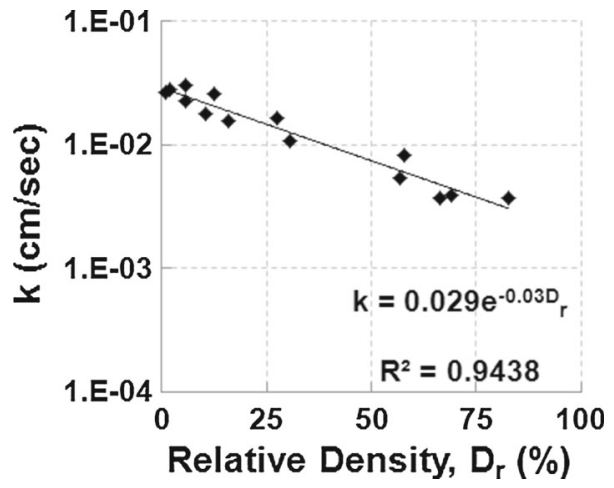


The measured cone data $\mathrm{q}_{\mathrm{c}}$ and $\mathrm{f}_{\mathrm{s}}$ were normalized based on the equations stated below:

$$
\begin{aligned}
\mathrm{q}_{\mathrm{c} 1 \mathrm{~N}} & =\frac{\mathrm{q}_{\mathrm{c} 1}}{\mathrm{P}_{\mathrm{a}}}=\mathrm{C}_{\mathrm{q}}\left(\frac{\mathrm{q}_{\mathrm{c}}}{\mathrm{P}_{\mathrm{a}}}\right) \\
\mathrm{F} & =\frac{\mathrm{f}_{\mathrm{s}}}{\mathrm{q}_{\mathrm{c}}-\sigma_{\mathrm{v}}}
\end{aligned}
$$

where $\mathrm{C}_{\mathrm{q}}=\left(\frac{\mathrm{P}_{\mathrm{a}}}{\sigma_{\mathrm{vo}}^{\prime}}\right)^{\mathrm{n}}$, if $\left(\frac{\mathrm{P}_{\mathrm{a}}}{\sigma_{\mathrm{vo}}^{\prime}}\right)^{\mathrm{n}}>1.7$ then $\mathrm{C}_{\mathrm{q}}=1.7$ if not then $\mathrm{C}_{\mathrm{q}}=\left(\frac{\mathrm{P}_{\mathrm{a}}}{\sigma_{\mathrm{vo}}^{\prime}}\right)^{\mathrm{n}} ; \mathrm{q}_{\mathrm{c} 1}=$ normalized CPT tip resistance corrected for effective overburden stresses corresponding to $1 \mathrm{ton} / \mathrm{ft}^{2}$ (100 $\left.\mathrm{kN} / \mathrm{m}^{2}\right) ; \mathrm{P}_{\mathrm{a}}=$ atmospheric pressure in the same units used for $\mathrm{q}_{\mathrm{c}}$; and $\mathrm{n}=$ stress exponent that varies from 0.5 to 1.0 , depending on the soil behavior type. In this study, the " $n$ " value was taken as 0.5 (value for the clean sand).

The increase in relative density results a significant reduction in compressibility. After determination of the hydraulic conductivity and compressibility corresponding to intended relative density, the coefficient of consolidation $\left(c_{v}\right)$ was estimated from the following equation:

$$
\mathrm{c}_{\mathrm{v}}=\frac{\mathrm{k}}{\mathrm{m}_{\mathrm{v}} \cdot \gamma_{\mathrm{w}}}
$$

where $\gamma_{\mathrm{w}}$ is the unit weight of water. The coefficient of consolidation obtained from the above equation range from $2 \times 10^{4}$ to $2 \times 10^{5} \mathrm{~mm}^{2} / \mathrm{s}$ for each shake. As coefficient of consolidation is one of the important factors in this study, it is essential to compare the coefficient of consolidations determined from the empirical correlations with the evaluated $\mathrm{c}_{\mathrm{v}}$ values from the post-shake settlement and the excess of pore pressure distributions. The $c_{v}$ values calculated from the $1 \mathrm{D}$ consolidation theory ranged from $10^{4}$ to $8 \times 10^{4} \mathrm{~mm}^{2} / \mathrm{s}$. Hence, the calculated results fairly accord with the estimated coefficient of consolidation from CPTu tests.

\section{Effect of consolidation characteristics on liquefaction and re-liquefaction resistance}

Given these observations, we can determine the influence of the consolidation characteristics to liquefaction and re-liquefaction resistance at different cyclic loading conditions. From CSR 0.11 to 0.46 , destruction of the loose soil (relative density from 15 to $40 \%$ ) during the initial liquefaction tests caused a significant increase in relative density from 35 to $60 \%$ (Fig. 9a). Figure 11a illustrates the compressibility and hydraulic conductivity before and after the first shakings at four different cyclic demands. As shown in the figure, significant densification results in a decrease in hydraulic conductivity and compressibility of the loosely packed sand columns following the first shakings. The filled circle symbols refer to the depths where the number of cycles required to cause second liquefaction, $\left(\mathrm{N}_{\mathrm{L}}\right)_{2}$ is smaller than the number of cycles required to cause first liquefaction, $\left(\mathrm{N}_{\mathrm{L}}\right)_{1}$. The values of $\left(\mathrm{N}_{\mathrm{L}}\right)_{1}$ and $\left(\mathrm{N}_{\mathrm{L}}\right)_{2}$ for each shaking tests, at the corresponding depths, are documented in Fig. $9 \mathrm{~b}$. The combined effect of a significant reduction in compression and hydraulic conductivity following the first shaking caused sand columns to re-liquefy more readily during the second shaking, despite a significant increase in relative density. On the other hand, a relatively small decrease in compressibility and hydraulic conductivity of the loose soil provided higher second liquefaction resistance. The unfilled circle symbols refer to the depths where the second liquefaction resistance observed higher than the first liquefaction resistance at each CSR. The effect of hydraulic conductivity and compressibility of the sand was captured by 
(a)

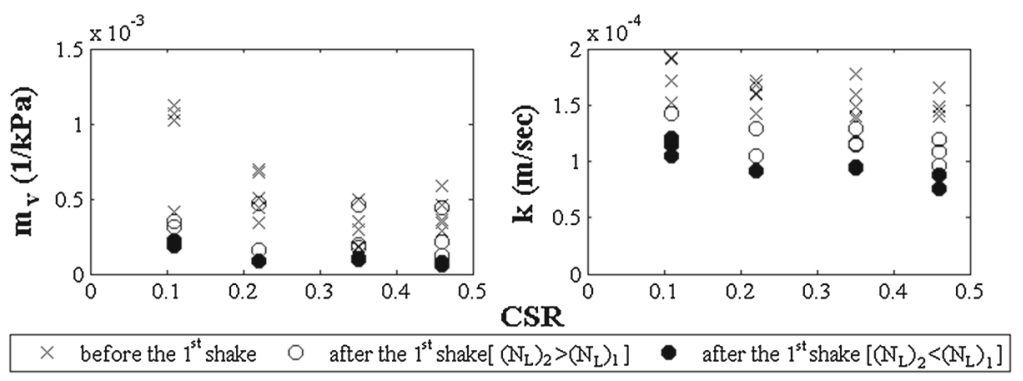

(b)
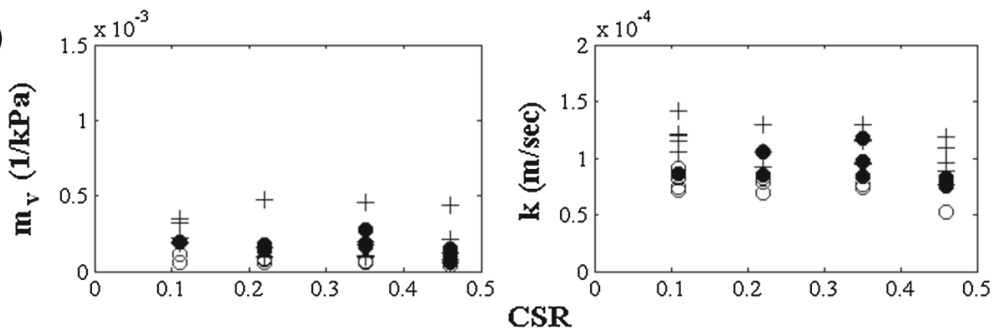

+ before the $2^{\text {nd }}$ shake (after the $1^{\text {st }}$ shake) $\bigcirc$ after the $2^{\text {nd }}$ shake $\left[\left(\mathrm{N}_{L}\right)_{3}>\left(\mathrm{N}_{\mathrm{L}}\right)_{2}\right]$

after the $2^{\text {nd }}$ shake $\left[\left(\mathrm{N}_{\mathrm{L}}\right)_{3}<\left(\mathrm{N}_{\mathrm{L}}\right)_{2}\right]$

Fig. 11 For CSR of $0.11,0.22,0.35$ and 0.46 , variation of the compressibility and hydraulic conductivity of the sand deposit before and after (a) first and (b) second shaking tests

the coefficient of consolidation. As shown in Fig. 12a, the ratio of $\left(\mathrm{N}_{\mathrm{L}}\right)_{2} /\left(\mathrm{N}_{\mathrm{L}}\right)_{1}$ are plotted against the coefficient of consolidation for four different cyclic loadings. The coefficient of consolidation values given in the figure was determined after the first liquefaction test. As shown in the figure, the ratio of $\left(\mathrm{N}_{\mathrm{L}}\right)_{2} /\left(\mathrm{N}_{\mathrm{L}}\right)_{1}$ decreased as post-liquefaction consolidation increased. From CSR 0.11 to 0.46 , the second liquefaction resistance determined smaller than the first liquefaction resistances when the post-liquefaction consolidation was greater than about $5 \times 10^{4}-10^{5} \mathrm{~mm}^{2} / \mathrm{sec}$, respectively.

From CSR 0.11 to 0.46 , destruction of the medium dense sand columns (relative density from 35 to $60 \%$ ) during the second shaking tests caused an additional increase in relative density (Fig. 9a). Figure 11b shows the compressibility and hydraulic conductivity before and after the second shakings at four different cyclic demands. As presented in the figure, an increase in relative density results in a relatively small decrease in hydraulic conductivity and compressibility of the medium dense sand deposits following the second shakings. The filled circle symbols illustrate the depths where the number of cycles required to cause third liquefaction, $\left(\mathrm{N}_{\mathrm{L}}\right)_{3}$ is smaller than the number of cycles required to cause second liquefaction, $\left(\mathrm{N}_{\mathrm{L}}\right)_{2}$. The values of $\left(\mathrm{N}_{\mathrm{L}}\right)_{3}$ and $\left(\mathrm{N}_{\mathrm{L}}\right)_{2}$ for each shaking tests, at the corresponding depths, are documented in Fig. 9b. Following the second shakings, a slight reduction in compressibility and hydraulic conductivity produced the third liquefaction resistance smaller than the second liquefaction resistance. On the other hand, combine effect of medium dense relative density with relatively large reduction in compressibility and hydraulic conductivity provided higher third liquefaction resistance. As a result, the third liquefaction resistance was determined larger than the second liquefaction resistance. The unfilled circles refer to the depths where the third liquefaction resistance observed bigger than the second liquefaction resistance for each shaking tests. Figure $12 \mathrm{~b}$ shows the ratio of $\left(\mathrm{N}_{\mathrm{L}}\right)_{3} /\left(\mathrm{N}_{\mathrm{L}}\right)_{2}$ against the coefficient of consolidation for four different cyclic loadings. The coefficients of consolidation values given in Fig. 12b were determined following the second liquefaction test. As shown in the figure, the ratio of $\left(\mathrm{N}_{\mathrm{L}}\right)_{3} /\left(\mathrm{N}_{\mathrm{L}}\right)_{2}$ increased as post-liquefaction consolidation of the sand 


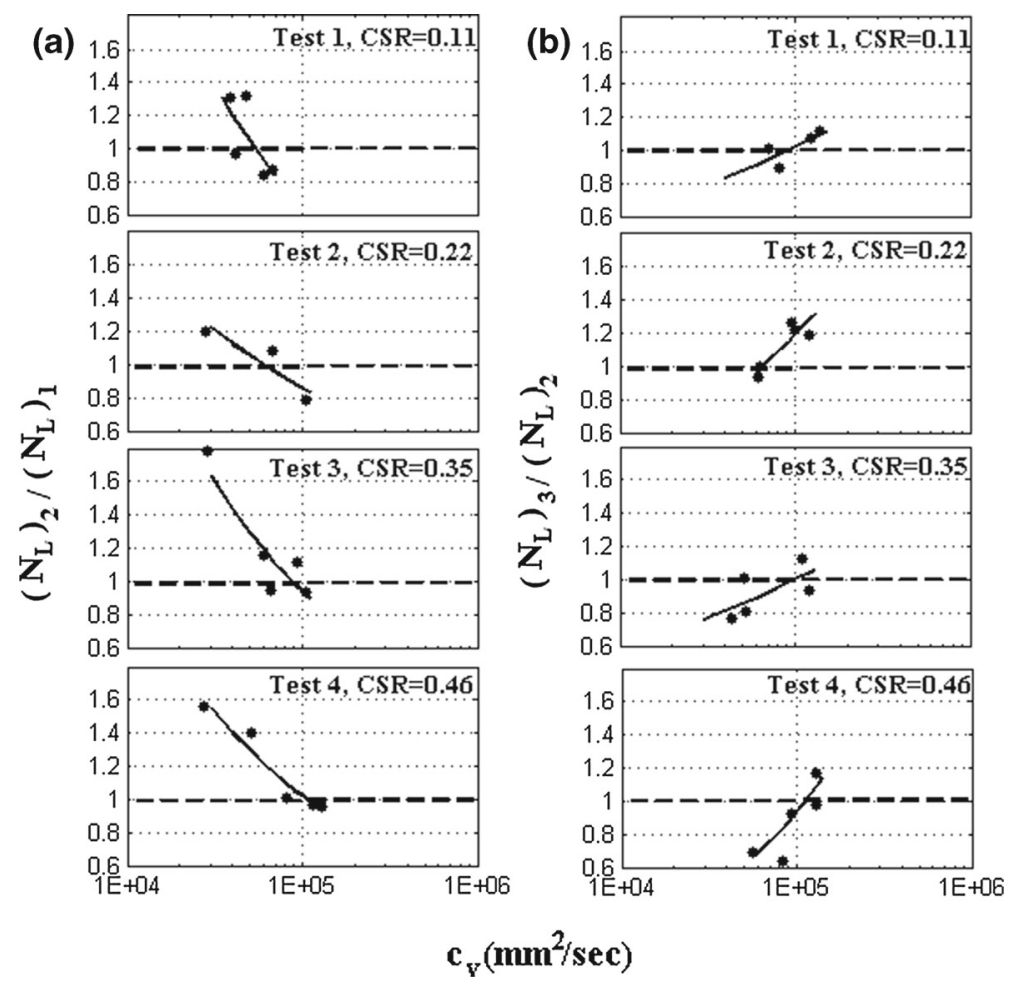

Fig. 12 The variation of (a) $\left(\mathrm{N}_{\mathrm{L}}\right)_{2} /\left(\mathrm{N}_{\mathrm{L}}\right)_{1}$ and (b) $\left(\mathrm{N}_{\mathrm{L}}\right)_{3} /\left(\mathrm{N}_{\mathrm{L}}\right)_{2}$ with coefficient of consolidation for CSR of $0.11,0.22,0.35$ and 0.46

increased. From CSR 0.11 to 0.46 , the third liquefaction resistance determined greater than the second liquefaction resistances for the post-liquefaction consolidation more than about $6 \times 10^{4}-10^{5} \mathrm{~mm}^{2} / \mathrm{s}$, respectively.

Hence, these results show that the liquefaction and re-liquefaction resistances not only depend on the relative density, but also on the particle interlocking and coefficient of consolidation, which depend on the hydraulic conductivity and the compressibility of the sand deposits. The test results also show that different cyclic loadings do not significantly affect the limit coefficient of consolidation value, where the re-liquefaction resistance is smaller than the liquefaction resistance. We also compared these outcomes with the results of Ha et al. (2011), who performed a series of shake table tests at the same cyclic loading (peak amplitude of $0.15 \mathrm{~g}$ ). They conducted cyclic tests using the five different gradation characteristics sands. They found that, at each sand deposit, the re-liquefaction resistance increases significantly when the coefficient of consolidation exceeds about $10^{4} \mathrm{~mm}^{2} / \mathrm{s}$. The difference in the determined limit coefficient of consolidation value in their study might depend on the difference at CSR and the effective grain size characteristics (hydraulic conductivity) of the tested sand deposits.

\section{Conclusion}

The saturated sand deposits, which had been liquefied previously, could be liquefied again at smaller cycles by the same seismic demand even though the relative density of the soil 
increased significantly. In order to understand the effect of relative density and consolidation characteristics on the liquefaction and re-liquefaction potential of fine silica sand (effective grain size of 0.12), we prepared four samples inside the laminar box. A total of four shaking table tests were performed at different shaking intensities. At each seismic demand, the input excitation was imposed three times. Based on the test results, the features can be summarized as follows:

1. The liquefaction and re-liquefaction resistances not only depend on the relative density, but also on the consolidation characteristics of the sand. Following the first shaking, at several depths, we observed substantial reduction in compression and hydraulic conductivity of the loose sand. This extensive reduction in compression and hydraulic conductivity caused $\left(\mathrm{N}_{\mathrm{L}}\right)_{2}$ to be smaller than $\left(\mathrm{N}_{\mathrm{L}}\right)_{1}$. The coefficient of consolidation captures the effect of hydraulic conductivity and compressibility of the sand. Thus, for each shaking intensity, $\left(\mathrm{N}_{\mathrm{L}}\right)_{2}$ determined smaller than $\left(\mathrm{N}_{\mathrm{L}}\right)_{1}$ when the post-liquefaction consolidation of the sand was greater than about $5 \times 10^{4}-10^{5} \mathrm{~mm}^{2} / \mathrm{s}$.

2. At several depths, the second liquefaction resistance is documented bigger than the third liquefaction resistance. At these same depths, we also detected slight reduction in compressibility and hydraulic conductivity of the medium dense soil. For each shaking intensity, $\left(\mathrm{N}_{\mathrm{L}}\right)_{3}$ determined smaller than $\left(\mathrm{N}_{\mathrm{L}}\right)_{2}$ for the post-liquefaction consolidation less than about $6 \times 10^{4} \mathrm{~mm}^{2} / \mathrm{sec}$ to $10^{5} \mathrm{~mm}^{2} / \mathrm{s}$.

3. Different cyclic loadings do not significantly affect the limit coefficient of consolidation value, where the re-liquefaction resistance is smaller than the liquefaction resistance.

4. Depending on the effective particle size of the sand deposit, this limit coefficient of consolidation value might change. Therefore, it is believed that further liquefaction and re-liquefaction tests on different grain sized sands are needed in order to find the limit coefficient of consolidation values.

Acknowledgments This research was supported by the TUBITAK Project No: 111M435. These supports are gratefully acknowledged. The authors wish to thank Asst. Prof. Gursoy Turan and Asst. Prof. Selcuk Saatci, for their helps in conducting tests on the shaking table which exists at Izmir Institute of Technology (IZTECH) structural engineering laboratory.

\section{References}

Castro G, Poulos SJ (1977) Factors affecting liquefaction and cyclic mobility. J Geotech Eng Div 103:501-516 Ecemis N (2013) Simulation of seismic liquefaction: 1-g model testing system and shaking table tests. Eur J Environ Civil Eng 17(10):899-919

Fiegel GL, Kutter BL (1994) Liquefaction mechanism for layered soils. J Geotech Eng 120(4):737-755

Finn WDL, Bransby L, Pickering DJ (1970) Effect of strain history on liquefaction of sand. J Soil Mech Found Div 96(SM6): 1917-1934

Ha IS, Olson SM, Seo MW, Kim MM (2011) Evaluation of reliquefaction resistance using shaking table tests. Soil Dyn Earthq Eng 31:682-691

Ishihara K, Okada S (1978) Yielding of overconsolidated sand and liquefaction model under cyclic stress. Soils Found 18(1):57-72

Ishihara K, Okada S (1982) Effect of large preshearing on cyclic behavior of sand. Soils Found 22(3):109-125

Ishihara K, Yoshimine M (1996) Evaluation of settlements in sands following liquefaction during earthquakes. Soils Found 32(1):173-188

Jamiolkowski M, Ladd CC, Germaine JT, Lancellotta R (1985) New developments in field and laboratory testing of soils. In: Proceedings of the 11th international conference on soil mech and foundation engineering. Balkema Publisher, Rotterdam, pp 57-153

Koloski JW, Schwarz SD, Tubbs DW (1989) Geotechnical properties of geologic materials. Wash Div Geol Earth Resour Bull 78(1):1-2 
Kulhawy FH, Mayne PW (1990) Manual on estimating soil properties for foundation design. Report EL-6800, Electric Power Research Institute, Palo Alto

Lee KL, Fitton JA (1969) Factors affecting the cyclic loading strength of soil. Vib Eff Earthq Soils Found ASTM STP 450:71-95

Lee KL, Albaisa A (1974) Earthquake-induced settlements in saturated sands. J Soil Mech Found Div 100(4):387-400

Mesri G, Feng TW, Benak JM (1990) Post-densification penetration resistance of clean sands. J Geotech Eng 116(GT7):1095-1115

Mitchell JK, Lee KM, Shen CK, Leung DHK (1999) Effects of placement method on geotechnical behavior of hydraulic fill sands. J Geotech Geoenviron Eng 125(10):832-846

Mulilis JP, Arulanandan K, Mitchell JK, Chan CK, Seed HB (1977) Effects of sample preparation on sand liquefaction. J Geotech Eng Div 103(2):91-108

Oda M, Kawamoto K, Fujimori H, Sato M (2001) Microstructural interpretation on reliquefaction of saturated granular soils under cyclic loading. J Geotech Geoenviron Eng 127(5):416-423

Ohara S, Yamamoto T, Yurino H (1992) Experimental study on reliquefaction potential of saturated and deposit. Paper presented at the tenth world earthquake engineering conference, Balkema, Rotterdam

Olson SM, Green RA, Obermeier SF (2005) Geotechnical analysis of paleoseismic shaking using liquefaction effects: a major updating. Eng Geol 76:235-61

Parkin AK, Lunne T (1982) Boundary effects in the laboratory calibration of a cone penetrometer for sand. In: Proceedings of the 2nd European symposium on penetration testing, vol 2. ESOPT-II, Amsterdam, pp $761-768$

Phillips R, Valsangkar AJ (1987) An experimental investigation of factors affecting penetration resistance in granular soils in centrifuge modelling. Technical Report No CUED/D-Soils TR210, Cambridge University, UK

Poulos SJ, Hed A (1973) Density measurements in a hydraulic fill. Evaluation of relative density and its role in geotechnical projects involving cohesionless soils. ASTM STP 523:402-424

Renzi R, Corte JF, Bagge G, Gui M, Laue J (1994) Cone penetration tests in the centrifuge: experience of five laboratories. In: Proceedings of international conference centrifuge 94, Singapore, pp 77-82

Robertson PK, Campanella RG (1983) Interpretation of cone penetration tests, parts 1: sand. Can Geotech J 20(4):718-733

Robertson PK, Wride CE (1998) Evaluating cyclic liquefaction potential using the cone penetration test. Can Geotech J 35(3):442-459

Robertson PK (2009) Interpretation of cone penetration tests-a unified approach. Can Geotech J 46:1337-1355

Sanglerat G (1972) The penetrometer and soil exploration. Elsevier, Amsterdam

Seed HB, Idriss IM (1971) Simplified procedure for evaluating soil liquefaction potential. J Soil Mech Found Div 97(9): 1249-1274

Schmertmann JH (1991) The mechanical aging of soils. J Geotech Eng 117:1288-1330

Suzuki T, Suzuki T (1988) Effects of density and fabric change on reliquefaction resistance of saturated sand. J Jpn Geotech Soc 28(2):187-195

Tatsuoka F, Ochi K, Fujii S, Okamoto M (1986) Cyclic undrained triaxial and torsional shear strength of sands for different sample preparation methods. Soils Found 6(3):23-41

Thevanayagam S, Kanagalingam T, Reinhorn A, Tharmendhira R, Dobry R, Pitman M, Abdoun T, Elgamal A, Zeghal M, Ecemis N, El Shamy U (2009) Laminar box system for 1-g physical modeling of liquefaction and lateral spreading. J ASTM Geotech Test 32(5):438-449

Tokimatsu K, Hosaka Y (1986) Effects of sample disturbance on dynamic properties of sand. Soils Found 26(1):53-64

Tokimatsu K, Seed HB (1987) Evaluation of settlements in sands due to earthquake shaking. J Geotech Eng 113(GT8):861-878

Whitman RV (1970) Hydraulic fills to support structural loads. J Soil Mech Found Div 96(SM1):23-47

Wong RT, Seed HB, Chan CK (1975) Cyclic loading liquefaction of gravelly soils. J Geotech Geoenviron Eng 101(6):561-583

Yasuda S, Tohno I (1988) Sites of reliquefaction caused by the 1983 Nihonkai-Chubu earthquake. Soils Found 28(2):61-72 